FOLIA

Amazónica

Revista del Instituto de Investigaciones

de la Amazonía Peruana

\title{
EFECTO DE DIFERENTES CONCENTRACIONES DE BENCILAMINOPURINA EN LA MICROPROPAGACIÓN DE DOS VARIEDADES DE AJÍES NATIVOS (Capsicum chinense Jacq.) EN PUCALLPA
}

\author{
Pablo Pedro VILLEGAS PANDURO ${ }^{1 *}$, Teresa ALARCÓN CASTILLO², \\ Melvin Elvis RODRÍGUEZ ORÉ ${ }^{1}$
}

1 Universidad Nacional de Ucayali (UNU), Carretera Federico Basadre km 6,2, distrito de Callería, provincia de Coronel Portillo, Ucayali, Perú.

2 Universidad Nacional Intercultural de la Amazonía (UNIA). Carretera San José de Tushmo km 0,63, Yarinacocha, Ucayali, Perú.

* Correo electrónico: ppvillegasunu@gmail.com

\section{RESUMEN}

Se verificó el efecto de diferentes concentraciones de Bencilaminopurina (BAP) en la micropropagación de ajíes nativos (ají dulce y ají pucunucho). Semillas fueron desinfectadas con hipoclorito de sodio al $2 \%$ por 30 minutos, enjuagadas con agua destilada estéril y sembradas en medio de cultivo con sales y vitaminas de Murashige y Skoog, suplementados con $30 \mathrm{~g} \mathrm{~L}^{-1}$ de sacarosa, $11 \mathrm{~g} \mathrm{~L}^{-1}$ de agar y sin reguladores de crecimiento. Después de 45 días de desarrollo in vitro, las plántulas fueron transferidas al medio Murashige y Skoog adicionando diferentes concentraciones de BAP ( 0 ppm, 0,5 ppm, 1 ppm y 1,5 ppm). Se concluye que la higienización de las semillas de ají dulce y ají pucunucho con hipoclorito de sodio $2 \%$ por 30 minutos generó $100 \%$ de semillas sanas. Las concentraciones de BAP estudiadas fueron eficaces para el aumento en la longitud de tallos, número de raíces, número de hojas, nudos y formación de callos en plántulas de ají dulce. En cambio, para las plántulas de ají pucunucho el aumento del número de hojas, nudos y raíces se dio en ausencia de concentraciones de BAP, a excepción de la generación de tejido calloso.

PALABRAS CLAVE: citoquininas, propagación clonal, hormonas vegetales, explantes, chiles. 


\title{
EFFECT OF DIFFERENT CONCENTRATIONS OF BENZYLAMINOPURINE ON THE MICROPROPAGATION OF TWO VARIETIES OF NATIVE CHILI (Capsicum chinense Jacq.) IN PUCALLPA
}

\begin{abstract}
The effect of different concentrations of Benzylaminopurine (BAP) on the micropropagation of native chili (sweet chili and pucunucho chili) was verified. Seeds were disinfected with $2 \%$ sodium hypochlorite for 30 minutes, rinsed with sterile distilled water and sown in culture medium with salts and vitamins from Murashige \& Skoog, supplemented with $30 \mathrm{~g} \mathrm{~L}^{-1}$ of sucrose, $11 \mathrm{~g} \mathrm{~L}^{-1}$ of agar and without growth regulators. After 45 days of in vitro development, the seedlings were transferred to Murashige \& Skoog medium, adding different concentrations of BAP ( 0 ppm, $0.5 \mathrm{ppm}, 1 \mathrm{ppm}$ and $1.5 \mathrm{ppm})$. It is concluded that the sanitization of the seeds of sweet chili and pucunucho chili with $2 \%$ sodium hypochlorite for 30 minutes generated $100 \%$ of healthy seeds. The concentrations of BAP studied were effective for the increase in the length of stems, number of roots, number of leaves, nodes and callus formation in sweet chili seedlings. On the other hand, for the seedlings of pucunucho chili, the increase in the number of leaves, nodes and roots occurred in the absence of concentrations of BAP, except for the generation of callus tissue.
\end{abstract}

KEYWORDS: cytokinins, clonal propagation, plant hormones, explants, chili peppers. 


\section{INTRODUCCIÓN}

El género Capsicum (Solanaceae) se constituye entre las plantas más antiguas que fueron cultivadas en América Precolombina. Las evidencias datan de 6500 a 5500 años a. C. en México y de 6 100 a. C. en Ecuador, lo que demuestra que ya eran utilizadas para el intercambio, consumo y como medicamento (Leite, 2015; Yánez et al., 2015).

Sin embargo, los restos de semillas de ají encontrados en el Perú proceden 8000 años a. C. en la cueva de Guitarrero-Yungay; 2500 a. C. en la Huaca Prieta (valle de Chicama) y 3000 a. C. en el Obelisco Tello (cultura Chavín) con representaciones de racimo de ají, así como en vasijas, huacos, mantos y textiles de otras culturas (Arellano, 2017).

De forma general, estudios taxonómicos muestran que existen más de 30 especies silvestres, de las cuales cinco especies han sido domesticadas con cuantiosas variedades como: Capsicum annuum L., Capsicum frutescens L.; Capsicum chinense Jacq., Capsicum pubescens Ruiz \& Pav. y Capsicum baccatum var. pendulum (Willd.) Eshbaugh (Trauco, 2019).

Actualmente, el Perú es uno de los países en el mundo que conserva una mayor variedad genética nativa del género Capsicum debido a la adaptación de los diferentes climas y suelos de la cordillera de los Andes, de la Costa y de la Amazonía por lo que pueden ser cultivados en altitudes que alcanzan los $2500 \mathrm{msnm}$ (Gonzales, 2018; Jara, 2018; Araya, 2019; Meza, 2020).

Además, existe una gran demanda en el mercado internacional de 19 variedades de ajíes nativos que pueden ser picantes o no picantes y son ingredientes favoritos en la gastronomía peruana como C. pendulum c.v. "ají escabeche"; $C$. chinense c.v. "pancca" у C. pubescens c.v. "rocoto" (Mendoza, 2006; López et al., 2020).

Según la Asociación de Exportadores (ADEX) (2018), en el Perú se estima que existen 10 mil productores, cuya producción alcanzó 160 mil toneladas al año, siendo que en el 2017 se exportó Capsicum por más de $\$ 238$ millones y las especies con mayor producción a nivel nacional fueron el morrón, ají nativo, rocoto, páprika y piquillo.

En la ciudad de Pucallpa, la Dirección Regional Agraria de Ucayali durante los años 2015 a 2016 incentivó el cultivo de 92 hectáreas de ají dulce, ayuyo y otros, obteniendo una producción total anual de $287 \mathrm{~kg}$ (Riva, 2019).

Siguiendo el contexto de la pluralidad genética, C. chinense tiene su origen en los trópicos amazónicos encontrándose algunas especies particulares que han alcanzado notoriedad en el mundo por su agradable sabor y elevado contenido de capsaicina (Puc, 2015).

También, se le atribuye un valor nutritivo ya que concentra fuentes importantes de fenoles, vitamina C, carotenoides (Rosario et al., 2021) y sales minerales como $\mathrm{Na}, \mathrm{Ca}, \mathrm{Fe}, \mathrm{K}, \mathrm{Zn}, \mathrm{Mg}, \mathrm{Mn}$ y $\mathrm{Cu}$ (Aguiar \& Souza, 2016). A su vez, se constituye excelente materia prima de muchas industrias para la elaboración de sprays para autodefensa (Gómez, 2016; Regla, 2017).

Por otro lado, se le han atribuido beneficios a la salud como antiinflamatorio, analgésico, con actividad antioxidante, antimutagénica, antitumoral, hipoglicémica, antifúngica y antimicrobiana (Salazar, 2016; Rodríguez, 2018; Morais, 2019; Rozete, 2019; Pineda et al., 2021); tornándose extraordinarios ingredientes en la industria farmacéutica y cosmética (píldoras, shampoos, cremas y pastas), debido a sus altas concentraciones de capsaicina (Baldeón \& Hernández, 2017; Guevara et al., 2017).

En años pasados las técnicas de cultivo de tejidos vegetales in vitro se han tornado promisorias para el control y diseminación de enfermedades que se presentan en diferentes etapas del cultivo y a su vez que permiten obtener semillas o plántulas de buena calidad (Camarena, et al., 2014; Días, 2017; Beltrán et al., 2019). 
Pero adversamente, el género Capsicum es considerado recalcitrante en términos de morfogénesis in vitro y regeneración vegetal, lo que ha limitado la aplicación de las técnicas de cultivo de tejidos. Por consiguiente, debido a estas dificultades se están realizando estudios (histológicos, bioquímicos y moleculares), además de la optimización de protocolos que aún son necesarios (Haque \& Ghosh, 2017; Izquierdo et al., 2017; Izgu et al., 2020).

Sin embargo, la micropropagación se muestra como una buena aliada para superar las dificultades enumeradas anteriormente, debido a que es ventajosa sobre la propagación tradicional, pues permite multiplicar in vitro plantas con nuevos genotipos, sanas y completamente homogéneas bajo estrictas condiciones de esterilidad, en un medio sintético nutritivo, con el control de temperatura, luz y fotoperiodo (Sharry et al., 2015; Hossain, 2018; Hernández et al., 2021).

La adición de reguladores de crecimiento en los medios de cultivo favoreció grandes progresos en las actuales técnicas biotecnológicas. En muchos experimentos sustancias sintéticas como la Bencilaminopurina (BAP) han sido utilizadas para suplir posibles deficiencias hormonales, ya que actúan sobre el metabolismo vegetal y son excelentes auxiliares en el crecimiento y cultivo de tejidos de determinadas especies vegetales (Oliveira, 2016; Paz, 2016).

Con todo lo expuesto, este estudio fue iniciado con el objetivo de verificar el efecto de las diferentes concentraciones de Bencilaminopurina (BAP) en el medio de cultivo Murashige y Skoog (MS) para la germinación y micropropagación de ajíes nativos (ají dulce y ají pucunucho).

\section{MATERIALES Y MÉTODOS}

\section{ÁREA DE ESTUDIO}

El ensayo fue ejecutado entre los meses de septiembre y octubre del 2019, se desarrolló en el Laboratorio de Cultivo de Tejidos y Meristemas de la Facultad de Ciencias Agropecuarias de la Universidad Nacional de Ucayali, localizado en la ciudad de Pucallpa, a 08 $23^{\circ}$ '39,6" de latitud sur y $74^{\circ} 34^{\prime} 39,8^{\prime \prime}$ de longitud oeste, a 154 msnm, en el km 6,2 de la carretera Federico Basadre, distrito de Callería, provincia de Coronel Portillo, departamento de Ucayali (Tolentino, 2019).

El clima de Pucallpa es de tipo cálido tropical, tiene una temperatura ambiental que oscila entre $18{ }^{\circ} \mathrm{C}$ en invierno y $34{ }^{\circ} \mathrm{C}$ en verano, la humedad relativa varía entre 80 y $100 \%$ durante todo el año (SENAMHI, 2020).

\section{MATERIAL VEGETAL}

Las semillas de las variedades de ajíes (Capsicum chinense Jacq.), se extrajeron de frutos obtenidos de los campos de producción de ajíes del Centro Poblado Pimental, distrito de Campo Verde, provincia de Coronel Portillo, región Ucayali, localizado a $08^{\circ} 31^{\prime} 19,52^{\prime \prime}$ de latitud sur y $74^{\circ}$ 48' 18,84" de longitud oeste, a 211 msnm, las cuales fueron lavadas y secadas bajo sombra por 2 días, y almacenadas durante 1 semana en bolsas de papel y conservadas a $4{ }^{\circ} \mathrm{C}$ hasta el momento del ensayo.

\section{DESINFECCIÓN}

Posteriormente fueron desinfectadas superficialmente dentro de una cabina de flujo láminar Telstar Aeolus $\mathrm{H}$, por inmersión en una solución de etanol $70 \%$ (v/v) durante 1 minuto, posteriormente transportadas a una solución de hipoclorito de sodio ( $\mathrm{NaClO}$ ) en una concentración de $2 \%$ por 30 minutos. Finalizado el tratamiento 
de desinfección, las semillas fueron enjuagadas cuatro veces con agua destilada estéril.

\section{CONDICIONES DE CULTIVO}

Las semillas fueron sembradas en medio de cultivo con sales y vitaminas de Murashige y Skoog, suplementado con $30 \mathrm{~g} \mathrm{~L}^{-1}$ de sacarosa y 11 $\mathrm{g} \mathrm{L}^{-1}$ de agar libre de reguladores de crecimiento. Posteriormente, fueron acondicionadas en cámara de crecimiento a $25^{\circ} \mathrm{C}, 75 \%$ de humedad, 2000 lux y fotoperiodo de $12 / 12$, durante 45 días, tiempo en el cual las semillas germinaron y se formaron las plántulas con hojas verdaderas.

\section{PREPARACIÓN DE MEDIO DE CULTIVO CON CONCENTRACIONES DE BAP}

Una vez germinadas las semillas fue preparado el medio de cultivo con sales y vitaminas de Murashige y Skoog, suplementado con $30 \mathrm{~g} \mathrm{~L}^{-1}$ de sacarosa y $11 \mathrm{~g} \mathrm{~L}^{-1}$ de agar, adicionando las concentraciones de BAP en estudio, como se muestra en la Tabla 1.

Tabla 1: Tratamientos con diferentes concentraciones de Bencilaminopurina (BAP) en medio Murashige y Skoog (MS) para evaluar el crecimiento de las variedades de ajíes

\begin{tabular}{lc}
\hline \multicolumn{1}{c}{ Variedades } & Concentraciones de BAP (ppm) \\
\hline Ají dulce & $0 ; 0,5 ; 1 ; 1,5$ \\
Ají pucunucho & $0 ; 0,5 ; 1 ; 1,5$ \\
\hline
\end{tabular}

\section{SIEMBRA DE FRAGMENTOS DE PLÁNTULAS IN VITRO}

Fragmentos de $1 \mathrm{~cm}$ de largo (con nudo y hoja verdadera) de las plántulas de ajíes germinadas in vitro fueron sembrados en frascos con medio de cultivo preparado anteriormente y llevados para su brotamiento por 45 días a $25^{\circ} \mathrm{C}, 2000$ lux y fotoperiodo de 12/12.

\section{ANÁLISIS ESTADÍSTICO}

Las observaciones fueron sometidas a un Diseño Completo al Azar (DCA) para cada variedad de ají nativo, 4 tratamientos de BAP y 6 repeticiones (plántulas) además de la aplicación de la prueba promedio de Tukey $(\alpha=0,05)$.

\section{RESULTADOS Y DISCUSIÓN}

Durante el proceso de desinfección de las semillas de ají dulce y ají pucunucho ( $C$. chinense Jacq.) para el cultivo in vitro, no fue necesario utilizar bactericidas o fungicidas. El tratamiento aséptico con hipoclorito de sodio (2\%) dio buenos resultados, semejantes procedimientos fueron obtenidos por otros investigadores (Fernandes, 2017; Hernández et al., 2019). Mientras Gayathri et al. (2015), emplearon leboleno y bavistina $(0,1 \%)$.

Por otra parte, dos tratamientos para desinfección de semilla con hipoclorito de sodio (2\% y 5\%) fueron realizados por GutierrezRossati \& Vega (2016), eligiendo la menor concentración debido a que es menos invasivo para la semilla. También observaron la viabilidad $(100 \%)$ de semillas obtenidas de frutos frescos distintamente de semillas secas comerciales (96\%) posiblemente conferido al tiempo de almacenamiento que experimentan en los estantes de ventas.

Las semillas de ají dulce y ají pucunucho cultivadas en medio MS fueron monitoreadas desde el inicio de la germinación hasta los 45 días de incubación, consecuentemente los porcentajes de germinación registrados no presentaron contaminación por hongos y bacterias $(0 \%)$, produciéndose plántulas sanas 100\% viables.

Por consecuencia Esposito-Polesi (2020), menciona que la contaminación normalmente acontece cuando los microrganismos no fueron 
Tabla 2: Evaluación del crecimiento in vitro de plántulas de ají dulce (Capsicum chinense Jacq.) bajo diferentes concentraciones de Bencilaminopurina (BAP) en medio Murashige y Skoog (MS).

\begin{tabular}{ccccccccc}
\hline Ají & BAP (ppm) & \multicolumn{2}{c}{ Longitud de tallo $(\mathbf{c m})$} & \multicolumn{2}{c}{$\begin{array}{c}\text { Número de hojas y } \\
\text { nudos }\end{array}$} & \multicolumn{2}{c}{ Número de raíces } & Callos \\
\hline & & 15 días & 45 días & 15 días & 45 días & 15 días & 45 días & 45 días \\
\cline { 3 - 9 } & 0 ppm & $1,05 a$ & $2,03 a$ & $2,33 \mathrm{~b}$ & $2,66 \mathrm{~b}$ & $1,33 \mathrm{a}$ & $1,33 \mathrm{a}$ & No \\
\multirow{2}{*}{ Dulce } & $0,5 \mathrm{ppm}$ & $1,5 \mathrm{a}$ & $2,65 \mathrm{a}$ & $4 \mathrm{a}$ & $5 \mathrm{a}$ & $0,83 \mathrm{a}$ & $1,5 \mathrm{a}$ & Sí \\
& $1 \mathrm{ppm}$ & $1,43 \mathrm{a}$ & $2,23 \mathrm{a}$ & $3,66 \mathrm{ab}$ & $4,5 \mathrm{a}$ & $0 \mathrm{a}$ & $0,33 \mathrm{a}$ & Sí \\
& $1,5 \mathrm{ppm}$ & $1,63 \mathrm{a}$ & $3,18 \mathrm{a}$ & $3,33 \mathrm{ab}$ & $4,83 \mathrm{a}$ & $0,83 \mathrm{a}$ & $0,83 \mathrm{a}$ & Sí \\
\hline
\end{tabular}

Letras iguales no presentan diferencias significativas. Tukey $\mathrm{p} \leq 0,05$

Tabla 3: Evaluación del crecimiento in vitro de plántulas de ají pucunucho (Capsicum chinense Jacq.) bajo diferentes concentraciones de Bencilaminopurina (BAP) en medio Murashige y Skoog (MS).

\begin{tabular}{|c|c|c|c|c|c|c|c|c|}
\hline \multirow[t]{2}{*}{ Ají } & \multirow[t]{2}{*}{ BAP (ppm) } & \multicolumn{2}{|c|}{ Longitud de tallo $(\mathrm{cm})$} & \multicolumn{2}{|c|}{$\begin{array}{l}\text { Número de hojas y } \\
\text { nudos }\end{array}$} & \multicolumn{2}{|c|}{ Número de raíces } & \multirow{2}{*}{$\begin{array}{l}\text { Callos } \\
45 \text { días }\end{array}$} \\
\hline & & 15 días & 45 días & 15 días & 45 días & 15 días & 45 días & \\
\hline \multirow{4}{*}{ Pucunucho } & 0 ppm & $1,75 \mathrm{a}$ & $2,75 \mathrm{a}$ & $4 a$ & $5 \mathrm{a}$ & $3,5 \mathrm{a}$ & $3,5 \mathrm{a}$ & No \\
\hline & 0,5 ppm & $1,55 \mathrm{a}$ & $2,26 a$ & $3 a b$ & $2,33 \mathrm{~b}$ & $2,33 b$ & $2,33 b$ & Sí \\
\hline & $1 \mathrm{ppm}$ & $1 \mathrm{a}$ & $2,5 \mathrm{a}$ & $2,5 b$ & $3 b$ & $1,5 \mathrm{c}$ & $1,5 \mathrm{c}$ & Sí \\
\hline & 1,5 ppm & $1,23 a$ & $2,2 \mathrm{a}$ & $3,16 a b$ & $3,5 a b$ & $0,16 d$ & $0,16 d$ & Sí \\
\hline
\end{tabular}

Letras iguales no presentan diferencias significativas. Tukey $p \leq 0,05$

eliminados por completo durante la limpieza del material vegetal o por fallas en la esterilización de herramientas, equipos, medios de cultivo, operador, etc.

En la Tabla 2, los promedios de longitud de tallo y número de raíces si bien no presentan diferencias significativas en todas las concentraciones de BAP y los días de incubación, expresan diferencias significativas en los promedios del número de hojas y nudos a concentraciones de 1 y 1,5 ppm de BAP, diferente de la formación de tejido calloso que fue estimulado en concentraciones de 0,$5 ; 1 \mathrm{y}$ 1,5 ppm de BAP durante los 45 días de incubación.
Similarmente, en los ensayos con $C$. chinense cv. Guaraci Cumari do Pará, realizados por Smozinski \& Santos (2019), fueron experimentados 0, 1, 2 y 4 ppm de 2,4-diclorofenoxiacético y BAP en medio MS adicionado de $30 \mathrm{~g} \mathrm{~L}^{-1}$ de sacarosa y $6 \mathrm{~g} \mathrm{~L}^{-1}$ de agar, siendo que la concentración de 2,5 ppm de BAP más 1 ppm de 2,4-D estimuló el $100 \%$ de la producción de callos durante 49 días.

En tanto los estudios con $C$. chinense variedad Carolina Reaper emplearon MS añadido de 0,5 ppm de BAP y 2 ppm de ácido -1-naftalenacetico los cuales produjeron el 95\% de formación de callo durante 30 días (Sherova et al., 2019). 
Análogo a los datos anteriores se observa que los promedios de longitud de tallo, número de hojas, nudos y raíces no fueron significativos, pero sí expresaron los mayores valores sin la adición de BAP, mientras que la formación de tejido calloso fue obtenida a partir de 0,$5 ; 1$ y 1,5 ppm de BAP durante los 45 días de crecimiento (Tabla 3).

Es probable que el uso de medios de cultivo suplementados con diferentes formulaciones de sustratos y sustancias de crecimiento menos o más concentrados durante el desarrollo de brotes, hojas, tallos, nudos y raíces permitan un brotamiento más eficiente y a la vez reducir el costo de los insumos utilizados en las técnicas de micropropagación in vitro.

Como lo observado por Kundu et al. (2015) quienes trabajando con semillas de $C$. chinensis cv. Bhut jolokia probaron que, el medio MS basal suplementado con $8 \mathrm{~g} \mathrm{~L}^{-1}$ de agar, $30 \mathrm{~g} \mathrm{~L}^{-1} \mathrm{de}$ sacarosa y 2,5 ppm de BAP fue capaz de inducir el crecimiento de 5,5 brotes, pero al adicionar 0,25 ppm de ácido indol acético AIA a la misma formulación, se obtuvieron 8,4 brotes en un plazo de 30 días.

De forma parecida los análisis de Gogoi et al. (2014) con C. chinense Jacq. cv. "Bhot jalakia", manifestaron que el medio MS suplementado con BAP 3 ppm y kinetina 13 ppm indujeron 5 brotes por explante despues de 30 dias.

Sin embargo, Gayathri et al. (2015) al determinar concentraciones de BAP (5 ppm) y AIA (1 ppm) provocaron el crecimiento de apenas 3,4 brotes y 10 hojas de $C$. chinense Jacq. (Naga King Chili) después de cuatro semanas de micropropagación in vitro.

Resultados diferentes fueron obtenidos por Jimarez-Montiel et al. (2018), quienes consiguieron 8 hojas y 2,20 raíces de Chili habanero cv. naranja al combinar MS 25\% adicionados de 7 $\mathrm{g} \mathrm{L}^{-1}$ de agar, $15 \mathrm{~g} \mathrm{~L}^{-1}$ de sacarosa y 1 ppm de ácido indol-3-butírico al alcanzar 49 dias.

Mientras que algunas investigaciones alcanzaron máxima inducción al usarse MS con 5 ppm de BAP y 0,5 ppm de AIA consiguiendo 5,2 y 4,05 brotes de $C$. chinense variedad Naga Chili en 20 y 45 dias respectivamente (Raj et al., 2015; Jamir et al., 2019).

De forma general, BAP ofrece una mejor respuesta para la inducción de brotes cuando se combina con una concentración baja de una auxina que cuando se usa sola (Meetei et al., 2017).

Ventajosamente, en otros estudios con semillas de $C$. chinensis var. Lot Bhot, las formulaciones del medio MS con 4 ppm de BAP y MS incrementado de 2,5 ppm de BAP, fueron necesarios para adquirir 8,3 brotes de 7,6 cm de longitud y 63,3 brotes de raíces, respectivamente (Bora et al., 2019).

Los efectos de diferentes concentraciones de BAP en la micropropagación in vitro, revelan que tanto el ají dulce como el ají pucunucho pueden desarrollarse con o sin la adición de un estimulador de crecimiento en el medio de cultivo, y/o probablemente sea más selectivo a otro tipo de citocininas en cuanto a sus exigencias nutricionales (Nogueira, 2015; Fernandes et al., 2019).

Es fundamental realizar varios estudios relacionados a la morfometría de los frutos y las semillas en la productividad, rendimiento, calidad, que a su vez nos llevaran a manejar con prudencia y responsabilidad los programas de mejoramiento genético y de conservación (Aliaga et al., 2019; López et al., 2020).

En el presente estudio, la formación de nuevos brotes, su elongación y enraizamiento se lograron en el mismo medio de cultivo, lo cual reduce la manipulación de las plántulas y los costos durante el período de cultivo in vitro de los explantes. 


\section{CONCLUSIONES}

El uso de $2 \%$ de hipoclorito de sodio por 30 minutos de exposición, sobre las semillas de las variedades de ajíes, generó $100 \%$ de semillas sanas.

Las concentraciones de BAP estudiadas fueron eficaces para aumentar la longitud de tallos, número de raíces, número de hojas, nudos y formación de callos en semillas de ají dulce.

En cambio, para las plántulas de ají pucunucho el aumento del número de hojas, nudos y raíces se dio en ausencia de concentraciones de BAP, a excepción de la generación de tejido calloso.

\section{REFERENCIAS BIBLIOGRÁFICAS}

Aguiar, J.P.L.; Souza, F.CH.A. 2016. Teor de vitamina $C$ e minerais em cultivares de pimentas $d a$ Amazônia. 68 Reunião anual da SBPC. (http:// www.sbpcnet.org.br/livro/68ra/resumos/ resumos/2208_1391aaca9c36e63931c56 bbcb8a4c7fd2.pdf). Acceso: 22/03/2021.

Arellano, S.L.G. 2017. El ají, patrimonio alimentario de América y la universalidad de su uso. Tesis de maestría, Universitat de Girona, España. 102pp.

Asociación de exportadores (ADEX). 2018. Adex: Capsicum tienen mayor potencial por lo que se debe trabajar en su desarrollo. (https:// www.adexperu.org.pe/notadeprensa/adexcapsicum-tienen-mayor-potencial-por-loque-se-debe-trabajar-en-su-desarrollo/). Acceso: 22/03/2021.

Aliaga, J.; Portalatino, E.; Obregón, K.; Rodríguez, A.; Jiménez, J. 2019. Presencia del "ají nativo supano" (Capsicum chinense Jacq.) en el valle de Supe, Perú. Peruvian Agricultural Research, 1: 58-63. DOI: https://doi.org/10.51431/par. v1i2.584
Araya, E.A. 2018. Efecto de la densidad de siembra y el volumen del sustrato sobre la dinámica del agua en el hibrido de chile dulce (Capsicum annuun) Cv "Dulcitico" bajo invernadero en Alajuela, Costa Rica. Tesis de pre-grado, Universidad de Costa Rica, San José. 59pp.

Baldeón,S.A.;Hernández,W.G.2017.Identificación de la capsaicina y la deshidrocapsaicina en el extracto de oleorresina obtenido a partir del ají panca

(Capsicum chinense). Ingeniería Industrial, 35: 223-237. DOI: https://doi.org/10.26439/ing. ind2017.n035.1803

Beltrán, J.N; López, M.C.G.; Hernández, E.; Cruz, N. 2019. Germinación in vitro de chile chiltepín (Capsicum annuum L. var. glabriusculum) y regeneración por organogénesis. Agrociencia, 54: 195-208.

Bora, G.; Gogoi, H.K.; Handique, P.J. 2019. Influence of silver nitrate and glutamine on in vitro organogenesis of Lota Bhot (Capsicum chinense Jacq.), and indigenous pungent pepper variety of Assam. Journal of Applied Biology \& Biotechnology, 7(1): 21-28.

Camarena, F.; Chura, J.; Blas, R.H. 2014. Mejoramiento genético y biotecnológico de plantas. Banco Agropecuario. Lima, Perú. 277pp.

Dias, M.I. 2017. Cultura in vitro e técnicas de micro capsulação: aumento da produção e estabilidade da compostos bioativos de espécies vegetais. Tesis de doctorado, Universidade do Porto, Portugal. 322pp.

Esposito-Polesi, N. 2020. Contaminação versus manifestação endolítica: implicações no cultivo in vitro de plantas. Rodriguesia, 71: e00562018. DOI: https://doi.org/10.1590/2175-786020 2071072

Fernandes, M. 2017. Germinação e cultivo in vitro de três espécies do gênero Capsicum. 
Tesis de Pre-grado. Universidade Federal de Uberlândia, Minas Gerais - Brasil. 49pp.

Fernandes, M.; Gomes, B.; Nogueira, A. 2019. Indução de calos em explantes foliares e caulinares de Cumarí-do-Pará (Capsicum chinense Jacquin). Revista Agraria Académica, 2(6): 81-92. DOI: https://doi.org/10.32406/ v2n62019/81-92/agrariacad

Gayathri, N.; Gopalakrishnan, M.; Sekar, T. 2015. In vitro micropropagation of Capsicum chinense Jacq. (Naga King Chili). Asian Journal of Plant Science and Research, 5: 13-18.

Gogoi, S.; Acharjee, S.; Devi, J. 2014. In vitro plantlet regeneration of Capsicum chinense Jacq. cv. 'Bhut jalakia': hottest chili of Northeastern India. In Vitro Cellular \& Developmental Biology - Plant. 50: 235-241.

Gómez, L.M. 2016. Establecimiento de un protocolo para la inducción de la androgénesis en Capsicum chinense Jacquin. Tesis de maestría, Centro de Investigación Científica de Yucatán, Mérida. México. 76pp.

Gonzales, D.R. 2018. Viabilidad adaptativa de cuatro procedencias de chile silvestre (Capsisum annuum L. var glabriusculum) bajo el sistema de manejo agroforestal en huertas de guayabo (Psidiun guajava l.) en el Municipio de Calvillo, AGS. Tesis de maestría, Universidad Autónoma de Aguascalientes, México. 169pp.

Guevara, A.P.; Villanueva, E.Q.; Nolazco, D.C., Llontop, G.; Cancino, K.Ch. 2017. Efecto de la aplicación de vapor saturado como sistema de esterilización orgánica (OSS) en el ají mirasol (Capsicum baccatum var. pendulum) y en el ají panca (Capsicum chinense Jacq.). Enfoque UTE, 12(3): 1-10. DOI: https://doi.org/10.29019/ enfoqueute. 675

Gutierrez-Rosati, A.; Vega, B. 2016. Micropropagación in vitro de "Ají Mirasol", Capsicum baccatum var. pendulum. The Biologist (Lima), 14: 171-181. DOI: https:// doi.org/10.24039/rtb201614296
Haque, S.; Ghosh, B. 2018. An improved micropropagation protocol for the recalcitrant plant Capsicum: a study with ten cultivars of Capsicum spp. (C. annuum, C. chinense and $C$. frutescens) collected from diverse geographical regions of India and México. The Journal of Horticultural Science and Biotechnology, 93(1): 91-99. DOI: https://doi.org/10.1080/146203 16.2017.1345331

Hernández, A.D.A.; Pineda, A.J.L.; Diaz, H.B.P. 2019. Efecto de la luz y del ácido giberélico en la germinación in vitro de Capsicum annuum L. cv. "Papri King". Biotecnologia Vegetal, 19: 165-170.

Hernández, A.D.A.; Pineda, A.J.L.; Rojas, J.A.Ch.; Diaz, H.B.P. 2021. Regeneración in vitro de arnaucho (Capsicum chinense Jacq.) a partir de yemas apicales. Manglar, 18: 71-75. DOI: http://dx.doi.org/10.17268/ manglar.2021.009

Hossain, M. 2018. In vitro regeneration of pepper (Capsicum annuum L.). Master thesis, Sher-EBangla Agricultural University, Dhaka. India. 58pp.

Izgu, T.; Ilbi, H.; Mendi, Y. 2020. Optimization of plant regeneration in different pepper (Capsicum annuum L,) lines. Turkish Journal of Agriculture - Food Science and Technology, 8: 471-477. DOI: https://doi.org/10.24925/ turjaf.v8i2.471-477.3207

Izquierdo, H.O.; Alcaraz, L.M.; Rodríguez, M.A. 2017. Micropropagación de chiltepín (Capsicum annuum L. cv. 'glabriusculum') mediante el empleo de una oligosacarina de origen péctico. Acta Universitaria, 27(5): 34-43. DOI: https://doi.org/10.15174/ au.2017.1452

Jamir, S.; Maiti, C.S.; Walling, I. 2019. Plantlet regeneration of naga king chilli (Capsicum chinense Jacq.) from nodal segments through in vitro technique. Journal of Pharmacognosy and Phytochemistry, 8(4): 553-558. 
Jara, F. 2018. Efecto del abastecimiento hídrico en ambiente protegido sobre el rendimiento $y$ variables morfo-fisiológicas de chile (Capsicum annuum L.) y pepino (Cucumis sativus L.) en Heredia, Costa Rica. Tesis de Pre-grado, Universidad Nacional de Costa Rica, San José. 160pp.

Jimarez-Montiel, M.J.; Robledo-Paz, A.; OrdazChaparro, V.M.; Trejo-Téllez, Ll.; MolinaMoreno, J.C. 2018. Protocol for the reduction of costs in habanero chili (Capsicum chinense Jacq.) micropropagation. Pyton Revista Internacional de Botánica Experimental, 87: 94-104.

Kundu, S.; Das, A.; Moquammel Haque, S.K.; Ghosh, B. 2015. Chemotypic diversity in different Bhut jolokia fruits: in vitro conservation and mass propagation of superior ecotype. International Journal of Pharmaceutical Sciences Review and Research, 34(2): 47-53.

Leite, P.H. 2015. Analise de similaridade genética entre genotipos cultivados de Capsicum chinense utilizando marcadores RAPD. Tesis de Pre-grado, Universidade de Brasilia, Brasil. 28pp.

López, E.M.; López, A.Z.; Gil, A.E.R.; Mostacero, J.L.; De la Cruz, A.J.C.; Villena, L.Z. 2020. Morfometría de frutos y semillas del "ají mochero" Capsicum chinense Jacq. Ciencia y Tecnología Agropecuaria, 21(3): e1598. DOI: https://doi.org/10.21930/rcta.vol21_num3_ art:1598

Meetei, N.G.T.; Kumar Singh, A.; Mandal, N. 2017. Production of cucumber mosaicvirus free Naga King chili (Capsicum chinense Jacq.) by in vitro meristem tip culture. The Bioscan, 12(4): 1905-1909.

Mendoza, R. 2006. Sistemática e história del ají Capsicum Tourn. Universalia, 11: 80-88.

Meza, D.G.V. 2020. Obtención de líneas auto fecundadas de la colección de germoplasma de Capsicum sp en la provincia de Oxapampa, Tesis de Pre-grado, Universidad Nacional Daniel Alcides Carrión, Oxapampa. Perú. 132pp.

Morais, K. 2019. Bioatividade e potencial antioxidante da espécie Capsicum chinense na Amazonía Setentrional. Tesis de Doctorado, Universidade Federal de Roraima, Boa Vista. Brasil. 82pp.

Nogueira, W. 2015. Calogenesis e estabelecimento de suspensões celulares de Capsicum chinense Brs Moena. Tesis de Maestría. Fundação Universidade de Rondônia, Porto Velho. Brasil. 60pp.

Oliveira, L. 2016. Indução de calos em explantes foliares de chapéu de bispo Capsicum baccatum variedade pendulum. Tesis de Pre-grado, Faculdades Integradas Aparício Carvalho, Porto Velho, Brasil. 18pp.

Paz, E. 2016. Indução e dinâmica de crescimento de calos e de suspensão celulares de Capsicum frutescens $c V$, stromboli. Tesis de Maestría, Universidade de Rondônia, Porto Velho. Brasil. 59pp.

Pineda, A.J.L.; Argüelles, A.C.; Rojas, J.A.Ch.; Diaz, H.B.P. 2021. Respuesta en el establecimiento y regeneración in vitro de rocoto (Capsicum pubescens Ruiz \& Pav.). Aporte Santiaguino, 14: 31-42. DOI: https://doi.org/10.32911/as. 2021.v14.n1.745

Puc Chan, M.. 2015. Selección de fuentes parentales para el mejoramiento genético de chile habanero (Capsicum chinense Jacq.). Tesis de Maestría, Centro de Investigación Científica de Yucatán, Mérida. México. 75pp.

Raj, R.; Glint, V.D.; Babu, N. 2015. In vitro plant regeneration in Capsicum chinense Jacq, (Naga Chili). Journal of applied Biology and Biotechnology, 3: 030-033. DOI: http://dx.doi. org/10.7324/JABB.2015.3106

Regla, C. F. 2017. Análisis de la expresión de genes involucrados en la formación y desarrollo del meristemo caulinar en embriones cigoticos y somáticos de chile habanero (Capsicum 
chinense Jacq.) Tesis de Doctorado. Centro de Investigación Científica de Yucatán, Mérida. México. 107pp.

Riva, R.R. 2019. Manual del cultivo de ají charapita (Capsicum frutescens L.). Universidad Nacional de Ucayali, Pucallpa - Perú. 66pp.

Rodríguez De León, P.E. 2018. Determinación de capsaicinoides y compuestos fenólicos y su correlación con la capacidad de inhibición de $\alpha$-amilasa y $\alpha$-glucosidasa en dos variedades de Capsicum chinense Jacq cultivadas en invernadero en el estado de Nuevo León. Tesis de Maestria, Universidad Autónoma de León, Monterrey - México. 90pp.

Rosario, V.N.M.; Chaves, R.P.F.; Pires, I.V.; Santos, A.F.; Toro, M.J.U. 2021. Capsicum annuum e Capsicum chinense: características físicas, físicoquímicas, bioativas e atividade antioxidante. Brazilian Journal of Development, 7(5): 50414-50432. DOI: https://doi.org/ 10.34117/bjdv.v7i5.30060

Rozete, M.J.N. 2019. Caracterización fitoquímica y evaluación sensorial de chile habanero (Capsicum chinensis Jacq.) de Yucatán. Tesis de Maestría, Centro de Investigación Científica de Yucatán, Mérida - México. 124pp.

Salazar, E.A.S. 2016. Efecto bacteriostático y bactericida de extractos de ají panca (Capsicum chinense) y pimiento (Capsicum annuum var. annuum) sobre cultivos de Escherichia coli ATCC 25922 y Staphylococcus aureus ATCC 25923. Tesis de Pre-grado, Universidad Nacional Mayor de San Marcos, Lima. 99pp.

SENHAMHI (Servicio Nacional de Meteorología e Hidrología del Perú). 2020. Pronóstico del tiempo para Pucallpa (Ucayali). (https:// www.senamhi.gob.pe $/$ ? p = pronostico- detalle-turistico\&localidad=0024). Acceso: 10/11/2020.

Sharry, S.; Adema, M.; Abedini, W. 2015. Plantas de probeta. Manual para la propagación de plantas por tejidos in vitro. Universidad de la Plata, La Plata - Argentina. 241pp.

Sherova, G.; Palov, A.; Georgiev, V. 2019. Polyphenols profiles and antioxidant activities of extracts from Capsicum chinense in vitro plants and callus cultures. Food Science and Applied Biotechnology. 2(1): 30-37. DOI: https://doi.org/10.30721/fsab2019.v2.i1.56

Smozinski, C.V.; Santos, M.R.A. 2019. Indução de calos em explantes foliares, nodais e entrenodais de Capsicum chinense Jacq. cultivar "Guaraci Cumarí do Pará". South American Journal of Basic Education, Technical and Technological, 6(1): 145-155.

Tolentino, K.A. 2019. Determinación de las características fisicoquímicas y sensoriales del bombón de aguaje (Mauritia flexuosa L. f.) con diferentes coberturas de chocolate en Pucallpa. Tesis de Pre-grado, Universidad Nacional de Ucayali, Pucallpa. Perú. 65pp.

Trauco, C.V. 2019. Comportamiento productivo de ecotipos de rocoto (Capsicum pubescens) bajo tres densidades de siembra en el distrito de Molinopampa, provincia de Chachapoyas, región Amazonas, 2018. Tesis de Pre-grado, Universidad Nacional Toribio Rodríguez de Mendoza, Chachapoyas - Perú. 85pp.

Yánez, P.; Balseca, D.; Rivadeneira, L.; Larenas, C. 2015. Características morfológicas y de concentración de capsaicina en cinco especies nativas del género Capsicum cultivadas en Ecuador. La Granja: Revista de Ciencias de la Vida, 22: 12-32.

Recibido: 29 de enero de 2021 Aceptado para publicación: 1 de junio de 2021 